\title{
Constitutive expression of tdTomato protein as a cytotoxicity and proliferation marker for space radiation biology
}

\author{
Arif A. Chishti ${ }^{1}$, Christine E. Hellweg*, Thomas Berger, Christa Baumstark-Khan, \\ Sebastian Feles, Thorben Kätzel ${ }^{2}$, Günther Reitz \\ German Aerospace Center (DLR), Institute of Aerospace Medicine, Radiation Biology, Linder Höhe, D-51147 Köln, Germany
}

\section{A R T I C L E I N F O}

\section{Article history:}

Received 25 September 2014

Received in revised form 21 December 2014

Accepted 30 December 2014

\section{Keywords:}

Mammalian cells

Radiation response

Fluorescent protein

Cytotoxicity

Proliferation

tdTomato

\begin{abstract}
A B S T R A C T
The radiation risk assessment for long-term space missions requires knowledge on the biological effectiveness of different space radiation components, e.g. heavy ions, on the interaction of radiation and other space environmental factors such as microgravity, and on the physical and biological dose distribution in the human body. Space experiments and ground-based experiments at heavy ion accelerators require fast and reliable test systems with an easy readout for different endpoints. In order to determine the effect of different radiation qualities on cellular proliferation and the biological depth dose distribution after heavy ion exposure, a stable human cell line expressing a novel fluorescent protein was established and characterized. tdTomato, a red fluorescent protein of the new generation with fast maturation and high fluorescence intensity, was selected as reporter of cell proliferation. Human embryonic kidney (HEK/293) cells were stably transfected with a plasmid encoding tdTomato under the control of the constitutively active cytomegalovirus (CMV) promoter (ptdTomato-N1). The stably transfected cell line was named HEK-ptdTomato-N1 8. This cytotoxicity biosensor was tested by ionizing radiation (X-rays and accelerated heavy ions) exposure. As biological endpoints, the proliferation kinetics and the cell density reached $100 \mathrm{~h}$ after irradiation reflected by constitutive expression of the tdTomato were investigated. Both were reduced dose-dependently after radiation exposure. Finally, the cell line was used for biological weighting of heavy ions of different linear energy transfer (LET) as spacerelevant radiation quality. The relative biological effectiveness of accelerated heavy ions in reducing cellular proliferation peaked at an LET of $91 \mathrm{keV} / \mu \mathrm{m}$. The results of this study demonstrate that the HEK-ptdTomato-N1 reporter cell line can be used as a fast and reliable biosensor system for detection of cytotoxic damage caused by ionizing radiation.
\end{abstract}

(c) 2015 The Committee on Space Research (COSPAR). Published by Elsevier Ltd. All rights reserved.

\footnotetext{
Abbreviations: A260, absorbance at $260 \mathrm{~nm}$; A280, absorbance at $280 \mathrm{~nm}$; BP, bandpass; CEllRad, Cellular Responses to Radiation in Space; CMV, Cytomegalovirus; $\mathrm{Cu}$, copper; DMSO, dimethyl sulfoxide; DsRed, red fluorescent protein from Discosoma sp.; EGFP, Enhanced Green Fluorescent Protein; ESA, European Space Agency; F, fluence; FA, formaldehyde; FBS, fetal bovine serum; FT, "Farbteiler" - dichroic mirror; GANIL, Grand Accélérateur National d'Ions Lourds; GCR, galactic cosmic rays; Gy, Gray; GSI, GSI Helmholtzzentrum für Schwerionenforschung $\mathrm{GmbH}$; HEK/293, Human embryonic kidney; IBER, Investigations into Biological Effects of Radiation Using the GSI Accelerator Facility; ISS, International Space Station; LEO, low Earth orbit; LET, linear energy transfer; LP, longpass; MDR, multidrug resistance; MTT, 3-(4,5-dimethylthiazole-2-yl)-2,5-diphenyl tetrazolium bromide; NADH, reduced nicotinamide adenine dinucleotide; PBS, phosphate buffered saline; RBE, relative biological effectiveness; $\mathrm{RBE}_{50 \% \mathrm{PR}}$, $\mathrm{RBE}$ for $50 \%$ proliferation reduction; $\mathrm{SCR}$, solar cosmic rays; SpaceLife, Helmholtz Space Life Sciences Research School; Sv, Sievert; tdTomato, tandem dimer Tomato; $\mu \times \mathrm{g}$, microgravity.

* Corresponding author. Tel.: +49 2203601 3243; fax: +49 220361970.

E-mail addresses: arif.chishti@dlr.de (A.A. Chishti), christine.hellweg@dlr.de (C.E. Hellweg), thomas.berger@dlr.de (T. Berger), christa.baumstark-khan@dlr.de (C. Baumstark-Khan), sebastian.feles@dlr.de (S. Feles), tkaetzel@uni-bonn.de (T. Kätzel), guenther.reitz@dlr.de (G. Reitz).

1 Present address: Karachi Institute of Biology and Genetic Engineering (KIBGE), University of Karachi, Karachi-75270, Pakistan.
}

\section{Introduction}

Long stays in space, whether on the International Space Station (ISS) or on return flights to Moon or Mars, are not only a physical and mental challenge for the astronauts because of microgravity $(\mu \times \mathrm{g})$ and living in a confined environment, but are also associated with increased ionizing radiation exposure due to the complex natural radiation environment (Reitz, 2008). The ISS is located in low Earth orbit (LEO) at an altitude of approximately $415 \mathrm{~km}$ from the Earth's surface. The radiation field in LEO consists of solar cosmic rays (SCR), galactic cosmic rays (GCR) and trapped particles of the Earth's radiation belts, resulting in the presence of highly energetic protons, baryons, electrons, neutrinos, $\gamma$-rays, $\alpha$-particles (helium nuclei) and nuclei of atoms heavier than helium. Highly

\footnotetext{
2 Present address: Institut für Humangenetik, Biomedizinisches Zentrum, Universitätsklinikum Bonn, Sigmund-Freud-Str. 25, D-53127 Bonn, Germany.
} 
energetic particles of SCR and GCR, with high velocity and penetrance, represent a health risk for astronauts (Horneck et al., 2010). The radiation field inside the ISS is also highly variable due to the changes in ISS attitude, altitude and due to the local shielding environment for various sections inside the ISS, leading to absorbed dose values in the range of a few hundred $\mu \mathrm{Gray} /$ day $(\mu \mathrm{Gy} / \mathrm{d})$ inside and up to the $\mathrm{mGy} / \mathrm{d}$ range outside the ISS (Berger et al., 2013). The biological relevant dose (effective dose) as a prerequisite for human radiation risk assessment was determined applying relevant phantom experiments to be in the order of $\sim 550 \mu \mathrm{Siev}-$ ert/d ( $\mu$ Sv/d) for exposures inside the ISS (Puchalska et al., 2014).

The biological effects of ionizing radiation depend on its ability to ionize atoms or molecules. The most critical target of ionizing radiation within a cell is the cell nucleus, particularly DNA. DNA damage induced by ionizing radiation may lead to either early or late effects, such as carcinogenesis, if DNA repair is unsuccessful (Tubiana, 2009). Early after exposure or with a delay of days, ionizing radiation can elicit cell death. Dependent on radiation quality, dose, dose rate and cell type and status, ionizing radiation can cause different types of cell death and reduce cellular survival (Takashi, 2013; Panganiban et al., 2013; Yang et al., 2010; Pettersen et al., 2007). A commonly used parameter to describe radiation quality is the linear energy transfer $\left(\mathrm{LET}^{3}\right)$ in matter which depends on mass, charge and energy of the particles. For many biological endpoints including cell killing, it was shown that the relative biological effectiveness (RBE) of different heavy ions depends on LET with a peak at about $100-200 \mathrm{keV} / \mu \mathrm{m}$ (Cucinotta and Durante, 2006).

The effect of radiation on cell survival can be monitored by sensitive bioassays or reporter systems. Such bioassays will complement the physical detector systems used in space and on Earth, in view of the fact that they yield intrinsically biologically weighted measures of cellular responses to the complex radiation field for the space habitat. Previously conventional vital dyes and histological staining methods to examine membrane integrity were used as marker tools for growth determination. For example, the MTT test is used as a cost-effective standard assay to determine cell viability, cell growth and cytotoxicity. It requires the addition of 3-(4,5-dimethyethiazole-2-yl)-2,5-diphenyl tetrazolium bromide as substrate, which destroys the cells by formation of spicular crystals after reduction by cellular reducing agents such as reduced nicotinamide adenine dinucleotide (NADH) (Berridge et al., 2005). It has to be solubilized by addition of dimethyl sulfoxide (DMSO), therefore time-course experiments can only be carried out by repeated addition of the reagent to separate culture vessels (Rampersad, 2012). While addition of a substrate and cell lysis might still be feasible for screening of a large set of radiation qualities and biological depth-dose distribution tests (obviating the need for it would save time and resources), for space experiments, the development of a screening test with an inherent reporter is required. As liquid handling in space requires special devices and astronaut time is very limited, addition of a substrate and cell lysis have to be avoided in a space-suitable cytotoxicity test.

More recently, fluorescent proteins have become more common as their expression is instantaneous, quantitative, non-invasive in living tissues and it reduces the possibility of staining artifacts (Jiang et al., 2004). Fluorescence does not require any substrate or cofactor, it can easily be used in living cells to monitor signaling pathways (Davidson and Campbell, 2009; Verkhusha, 2001). Expression of fluorescent proteins can be meaningfully implemented in tumor cell research, including studies on metastasis and angiogenesis where real-time imaging can be used during therapeutic

\footnotetext{
3 LET is described as the average energy deposition $(\Delta E)$ on the beam path $(\Delta S)$ of an ion in matter, $\Delta E / \Delta S(\mathrm{keV} / \mu \mathrm{m})$.
}

studies and to understand the metastatic process and efficiency of potential therapeutics (Hoffman, 2005; Li et al., 1997). Constitutive expression of a fluorescent protein as a biomarker in reporter cell lines allows the quantification of toxin levels and aids in understanding mechanisms of toxicity (Baumstark-Khan et al., 2010).

Fluorescent protein spectrums range from UV-excitable green to far-red (Shaner et al., 2004, 2005). The discovery of the red fluorescent protein (DsRed) from the sea anemone Discosoma $s p$. has opened a new aspect of biological imaging (Campbell, 2002). Different variants of DsRed are widely used in reporter studies of gene expression and protein localization due to improved contrast and decreased phototoxicity, autofluorescence, and scattering (Davidson and Campbell, 2009; Hendriks et al., 2011). A whole family of fruit fluorescence proteins was constructed by altering DsRed, including the tandem dimer Tomato (tdTomato), mCherry and mStrawberry (Davidson and Campbell, 2009; Shaner et al., 2004). Shaner et al. improved the maturation kinetics through five rounds of directed evolution resulting in the extremely bright fluorescence of dTomato, a feature that makes the protein a desirable choice when visualizing a sparse target (Shaner et al., 2004). dTomato has the highest brightness (product of extinction coefficient, $138,000 \mathrm{Mol}^{-1} \mathrm{~cm}^{-1}$, and quantum yield, 0.69) at the cost of doubling the molecular weight (Shaner et al., 2004; Strongin et al., 2007). Two copies of the dTomato gene were fused together to create the tandem dimer tdTomato with excitation and emission maxima at 554 and $581 \mathrm{~nm}$, respectively (Hinterdorfer and van Oijen, 2009). This newly designed tdTomato showed better suitability and brighter florescence in cell imaging tasks and is exceptionally photostable because of its twin fluorophores. Therefore, a new test system using tdTomato was established to replace an earlier cytotoxicity assay using a promoter reporter system with Enhanced Green Fluorescent Protein (EGFP) (Hellweg et al., 2007a), originally isolated from the bioluminescent jellyfish Aequorea victoria (Shaner et al., 2008).

The aim of this study was to quantify cytotoxic effects of ionizing radiation by fluorescence measurement of tdTomato expressing HEK-ptdTomato-N1 cells. The fluorescence spectrum and intensity, and the growth kinetics of this cell line were determined. The newly constructed reporter system has a constitutively active promoter sequence that allows continuous expression of tdTomato and thereby growth determination after radiation exposure. As growth determination is linked with fluorescent protein synthesis the loss of tdTomato fluorescence following irradiation indicates cell death. Quantification of fluorescence in cells can be accomplished by different means, including the use of microplate readers, flow cytometry and digital fluorescence microscopy. The relative biological effectiveness (RBE) for growth reduction was compared for heavy ions of a broad LET range.

\section{Materials and methods}

\subsection{Plasmid cloning and preparation}

The plasmid ptdTomato-N1 (Fig. 2A) was obtained from Clontech (Palo Alto, USA). In this vector, the tdTomato gene is under control of the immediate early promoter of human Cytomegalovirus (CMV). The vector contains the aminoglycoside phosphotransferase gene referring kanamycin resistance in bacteria and G418 resistance in mammalian cells. Competent E. coli DH5 $\alpha$ cells were transformed for large scale plasmid preparation with the use of a Maxiprep Kit (Qiagen GmbH, Hilden, Germany). DNA concentrations (absorbance at $260 \mathrm{~nm}, \mathrm{A260}$ ) and protein contamination (absorbance at $280 \mathrm{~nm}$, A280) were measured using the spectrophotometer Nanodrop 2000c (Thermo Scientific, Langenselbold, Germany). In order to minimize contamination, only 

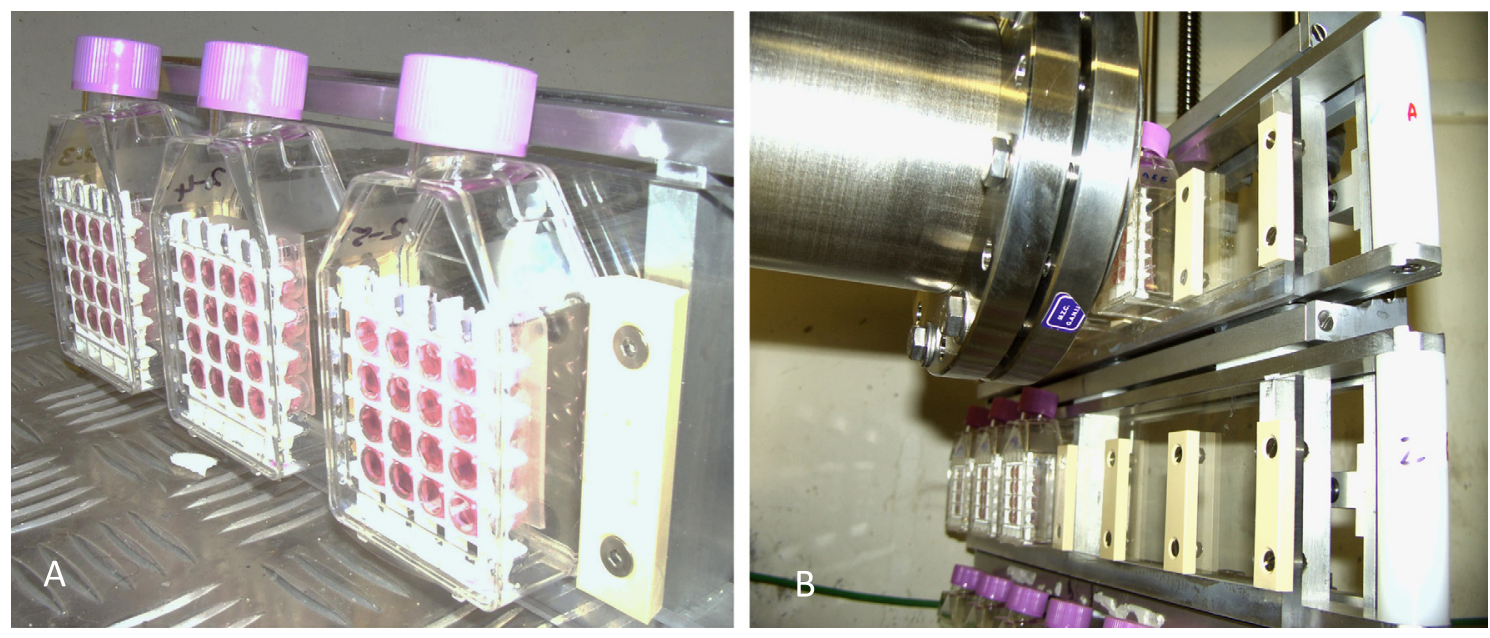

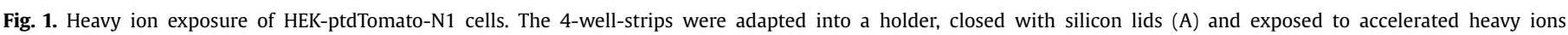
through the bottom of the well (B). Pictures were taken at GANIL in room D1, with the biological sample transporter in front of the beam exit.

preparations with an A260/A280 ratio over 1.8 were used for transfection of mammalian cells.

\subsection{Cell strains and culture conditions}

Human embryonic kidney (HEK/293, ATCC CRL-1859) cells were cultured according to standard procedures in $80 \mathrm{~cm}^{2}$ flasks (Nunc, Wiesbaden, Germany) in $\alpha$-medium (modified MEM, Pan-Biotech, Germany) with $10 \%$ fetal bovine serum (FBS) at $37^{\circ} \mathrm{C}$ in a saturated humidity and a $5 \% \mathrm{CO}_{2} / 95 \%$ air atmosphere. For weekly sub-cultivation, cell lines were washed with PBS before detaching with trypsin/EDTA solution (PAN Biotech, Aidenbach, Germany). Subsequently, cells were seeded at a density $3 \times 10^{4}$ cells $/ \mathrm{cm}^{2}$ in new flasks. Medium was changed every 4 days. To avoid detachment of HEK cells during experimental procedures, cell culture vessels (Petri dishes, microtiter plates) were coated with poly-Dlysine $\left(10 \mathrm{mg} / \mathrm{cm}^{2}\right.$, Sigma-Aldrich Chemie, Steinheim, Germany) for $15 \mathrm{~min}$ at $37^{\circ} \mathrm{C}$ and washed three times with sterile deionized water before use.

Enhanced green fluorescent protein expressing HEK-pEGFP-N1 cells (Hellweg et al., 2007a) were used for comparison and cultured in $\alpha$-medium with $10 \%$ FBS and $0.6 \mathrm{mg} / \mathrm{ml} \mathrm{G} 418$.

\subsection{Generation of a stably transfected reporter cell line}

HEK/293 cells were transfected with the ptdTomato-N1 vector using liposome-mediated DNA transfer (Fugene 6, Promega, Madison, WI, USA). The cells were seeded at a density of $3 \times$ $10^{4}$ cells $/ \mathrm{cm}^{2}$ into 24-well-plates (Falcon, Becton Dickinson Labware, Heidelberg, Germany) and incubated for 3 days. Semi confluent cell cultures were transfected following the instructions of the supplier. For stable transfection, the transfected cells were trypsinated $48 \mathrm{~h}$ after transfection, diluted 1:10 with medium containing $1.5 \mathrm{mg} / \mathrm{ml} \mathrm{G} 418$ (Calbiochem, La Jolla, CA, USA) and cultured in Petri dishes. After 10 days, G418 resistant cells were seeded in microplates at a concentration of 50 cells per plate and cultivated for 10-20 days. The resulting colonies were screened for tdTomato protein expression using the fluorescence microscope Axiovert 135 (Carl Zeiss, Oberkochen, Germany) as described in Section 2.8. Clones expressing tdTomato protein were reseeded into 24-wellplates. In addition, those that gave highest fluorescence without any morphological or growth change were selected by flow cytometry. From such stably transfected clones, the tdTomato expressing cell line HEK-ptdTomato-N1 8 was derived and maintained in medium containing $0.6 \mathrm{mg} / \mathrm{ml} \mathrm{G} 418$.

\subsection{Radiation exposure and proliferation determination}

HEK-ptdTomato-N1 8 cells were seeded two days before irradiation to reach a density of $20-30 \%$ at the time of irradiation. Cells were seeded into Costar 9102 strip well plates (Sigma-Aldrich Chemie) containing 8 wells per strip with each a growth area of $0.3 \mathrm{~cm}^{2}$ and a volume $320 \mu \mathrm{l}$. After seeding, the cells adhere to the bottom of the well. The wells were completely filled with cell culture medium immediately before irradiation and closed by means of sterile silicon lids (Abgene, Thermo Scientific, Schwerte, Germany). The 8-well strips were broken into pieces of 4 wells and positioned into specially designed holders (Fig. 1A) and irradiated as described below.

After irradiation, the strips were removed from the holders and the strips were reorganized into the 96-well-plate frame. The silicon lids were removed. Medium was changed, cells were incubated and growth of cells was followed by fluorescence measurement of tdTomato. Its fluorescence intensity was measured twice daily in the microplate reader for up to $\sim 100 \mathrm{~h}$ as explained in Section 2.9. For the final measurement at $\sim 100 \mathrm{~h}$ after irradiation, the dose effect curves for proliferation reduction were calculated as described in Section 2.10.

\subsubsection{X-ray exposure}

Cells were exposed to low LET $(0.3-3.0 \mathrm{keV} / \mu \mathrm{m}) \mathrm{X}$-rays using the Gulmay X-ray source RS225 (X-Strahl, Surrey, UK) at DLR Cologne. The X-ray tube was adjusted to $200 \mathrm{kV}$ and $15 \mathrm{~mA}$. To eliminate soft X-rays, a Copper $(\mathrm{Cu})$ filter with a thickness of $0.5 \mathrm{~mm}$ was used. Dose and dose rate were determined using the dosimeter UNIDOSwebline with the ionization chamber TM30013 (PTW, Freiburg, Germany). The distance of the sample from the X-ray source was set to $450 \mathrm{~mm}$ to provide a constant dose rate of $1.0 \mathrm{~Gy} / \mathrm{min}$. The temperature inside the X-ray chamber was kept at $37^{\circ} \mathrm{C}$ and samples were transferred after exposure to the incubator. As the X-ray source was located above the samples, cells in strips were exposed in horizontal position below the exit window.

\subsubsection{Accelerated heavy ions exposure}

Exposure to ${ }^{13} \mathrm{C}$ (LET $\left.33 \mathrm{keV} / \mu \mathrm{m}\right),{ }^{22} \mathrm{Ne}$ (LET $\left.91 \mathrm{keV} / \mu \mathrm{m}\right)$, ${ }^{56} \mathrm{Fe}($ LET $151 \mathrm{keV} / \mu \mathrm{m}),{ }^{58} \mathrm{Ni}$ (LET $175 \mathrm{keV} / \mu \mathrm{m}$ ) and ${ }^{58} \mathrm{Ni}$ (LET $905 \mathrm{keV} / \mu \mathrm{m}$ ) ions was performed at the Grand Accélérateur National d'Ions Lourds (GANIL, Caen, France) and the GSI Helmholtzzentrum für Schwerionenforschung GmbH (GSI, Darmstadt, Germany) as listed in Table 1.

The strips were exposed to the beam in upright position through the bottom of the vessel (Fig. 1B). At GSI, up to 9 sam- 
Table 1

Accelerated heavy ions and reference radiation used in this study.

\begin{tabular}{llcll}
\hline Ion & Location & $\begin{array}{l}\text { Energy } \\
(\mathrm{MeV} / \mathrm{n})\end{array}$ & $\begin{array}{l}\text { Energy on target }^{\mathrm{a}} \\
(\mathrm{MeV} / \mathrm{n})\end{array}$ & $\begin{array}{l}\text { LET } \\
(\mathrm{keV} / \mu \mathrm{m})\end{array}$ \\
\hline $\begin{array}{l}\text { X-rays } \\
{ }^{13} \mathrm{C}\end{array}$ & DLR & & & $0.5-3$ \\
${ }^{22} \mathrm{Ne}$ & GANIL & 75 & 71 & 33 \\
${ }^{56} \mathrm{Fe}$ & GANIL & 80 & 75 & 91 \\
${ }^{64} \mathrm{Ni}$ & GSI & 1000 & 997 & 151 \\
${ }^{58} \mathrm{Ni}$ & GSI & 1000 & 985 & 175 \\
\hline
\end{tabular}

a Effective irradiation energy at the cell monolayer after the energy losses in two detectors, the exit window, air (GANIL: $1 \mathrm{~cm}$, GSI: $100 \mathrm{~cm}$ ) and the bottom of the culture vessel $(1200 \mu \mathrm{m}$ polystyrene).

ples in sample holders were positioned on rectangular blocks on a conveyor belt and were transported in front of the beam. The correct positioning of the samples was verified by a video camera system. At GANIL, the sample holders were inserted in the biological sample racks in upright position (6 samples per rack). Four sample racks were inserted in the biological sample transporter and moved in front of the beam (Fig. 1B). As temperature control was not available at GSI and at GANIL, samples were irradiated at room temperature. The irradiation time per sample was up to $8 \mathrm{~min}$, depending on dose, and the total time in the irradiation room was $20-30 \mathrm{~min}$ at both facilities. Controls were treated as the irradiated samples except that they were not exposed to the beam. They were stored in the irradiation room in upright position for the same time as the irradiated samples.

Dosimetry was performed by the staff at the accelerator facilities and dose rates were adjusted to $\sim 1 \mathrm{~Gy} / \mathrm{min}$. The fluence (F) of heavy ions (particles $/ \mathrm{cm}^{2}, \mathrm{P} / \mathrm{cm}^{2}$ ) was converted to energy dose in Gy by the following formula under consideration of the linear energy transfer (LET, in kilo electron-volt, keV, per $\mu \mathrm{m}$ ) of the respective heavy ion:

Dose $[\mathrm{Gy}]=1.6 \times 10^{-9} \times \mathrm{LET}[\mathrm{keV} / \mu \mathrm{m}] \times \mathrm{F}\left[\mathrm{P} / \mathrm{cm}^{2}\right]$

\subsection{Growth determination}

For growth determination, HEK-ptdTomato-N1 8 cells were seeded into Petri dishes ( $\varnothing 3 \mathrm{~cm}$, Nunc, Wiesbaden, Germany) at a density of $1 \times 10^{4}$ cells $/ \mathrm{cm}^{2}$ and harvested by trypsination at regular time points. Cell numbers were determined by counting aliquots of the cell suspension in a counting chamber (Fuchs-Rosenthal). In comparison, cell growth was determined in the microplate reader as described in Section 2.9 after seeding HEK/293 and HEK-ptdTomato-N1 8 cells $\left(1 \times 10^{4}\right.$ cells $\left./ \mathrm{cm}^{2}\right)$ into 96-well-plates (Costar 3603, Corning Costar, Cambridge, MA, USA). Fluorescence measurements were performed at the same time points, while medium changes for both experiments were performed in an interval of every fourth day.

\subsection{Flow cytometry}

For flow cytometry, cells were detached from the growth surface using trypsin and fixed with $3 \mathrm{ml}$ ice-cold 3.5\% formaldehyde (FA) in phosphate buffered saline (PBS) for $30 \mathrm{~min}$. The FA was diluted with PBS (1:3) and cells were stored at $4{ }^{\circ} \mathrm{C}$. Prior to flow cytometric analysis, cells were centrifuged and resuspended in PBS. Forward and side scatter and tdTomato fluorescence (FL-2 channel, $565-606 \mathrm{~nm}$ ) of the samples were measured in a fluorescence activated cell scanner (FACScan, Becton Dickinson, San Jose, CA, USA) with an argon laser $(488 \mathrm{~nm})$ as excitation source and analyzed by the CellQuest software (version 1.2, Becton Dickinson, San Jose, CA, USA). $2 \times 10^{4}$ cells were analyzed at a rate of 200-600 cells per second. Forward and side scatter of the samples were set in a dotplot as a measure of cell size and granularity and a region of intact cells was defined. In the FL-2 histogram, the markers for tdTomato $^{(-)}$cells and tdTomato ${ }^{(+)}$cells were set by means of non-fluorescent and fluorescent cells within the gated intact cell population. The percentage of tdTomato $^{(+)}$cells was used as a measure of the fluorescent cell population.

\subsection{Fluorescence spectroscopy}

To determine the fluorescence excitation and emission spectra of tdTomato protein, a spectrofluorimeter (F-2700, Hitachi, Tokyo, Japan) was used. For measurement, $4 \times 10^{6}$ cells were fixed with 3.5\% FA in PBS, incubated for $30 \mathrm{~min}$, centrifuged and resuspended in $4 \mathrm{ml}$ PBS for analysis.

\subsection{Fluorescence microscopy}

The tdTomato expression in HEK-ptdTomato-N1 8 cells, cultivated on 16-well slides (Nunc, Wiesbaden, Germany), was visualized using an inverted fluorescence microscope (Axiovert 135, Carl Zeiss, Oberkochen, Germany), equipped with a filter set suitable for red fluorescence detection (Zeiss filter set 20, excitation BP $546 / 12 \mathrm{~nm}$, dichroic mirror FT 560, emission BP 575-640 nm). As excitation source, a mercury vapor short arc lamp (HBO $50 \mathrm{~W}$ type 4480 06, Carl Zeiss) was used. Photographs were taken by means of the high-resolution microscopy camera Mrc 5 and AxioVision Rel. 4.4 Software (Carl Zeiss).

\subsection{Fluorescence measurement in a microplate reader}

Fluorescence intensities of growing cells in 96-well-plates were determined using a microplate reader (Lambda Fluoro 320 plus, MWG Biotech, Ebersberg, Germany). The plates were measured without lid. tdTomato was detected with the optics positioned under the bottom of the plate and the filters 540/25 for excitation and $590 / 35$ for emission.

\subsection{Relative biological effectiveness}

The Relative Biologic Effectiveness (RBE) for proliferation reduction by heavy ions in comparison to X-rays was calculated from the regression lines of the dose-effect curves for growth reduction $100 \mathrm{~h}$ after radiation exposure. The doses-effect curves show the relative fluorescence dependent on radiation dose. Relative fluorescence of living cells was calculated by subtraction of background fluorescence of HEK cells, microplate bottom and cell culture medium $100 \mathrm{~h}$ after radiation exposure. For this purpose, two wells per dose were seeded with nontransfected HEK cells, and the mean of these two wells was subtracted from each well containing HEK-ptdTomato-N1 8 cells that were irradiated with this dose to correct for autofluorescence of cells. The background corrected fluorescence of the irradiated samples was normalized to the unirradiated control. For each dose effect curve, a regression curve was calculated using Sigma plot 12.0 and the dose reducing the relative fluorescence to $50 \%$ was derived (50\% proliferation reduction). The RBE for $50 \%$ proliferation reduction $\left(\mathrm{RBE}_{50 \% \mathrm{PR}}\right)$ was then calculated by dividing the required absorbed dose of X-rays (200 kV, reference radiation) by the absorbed dose of heavy ions (test radiation) using the following equation:

$\mathrm{RBE}_{50 \% \mathrm{PR}}=\frac{\text { Energy dose of X-rays }[\mathrm{Gy}]}{\text { Energy dose of heavy ion }[\mathrm{Gy}]}$

\subsection{Statistics}

Each experiment was repeated up to five times depending on the availability of beam time with one to six replicates each. Beam 

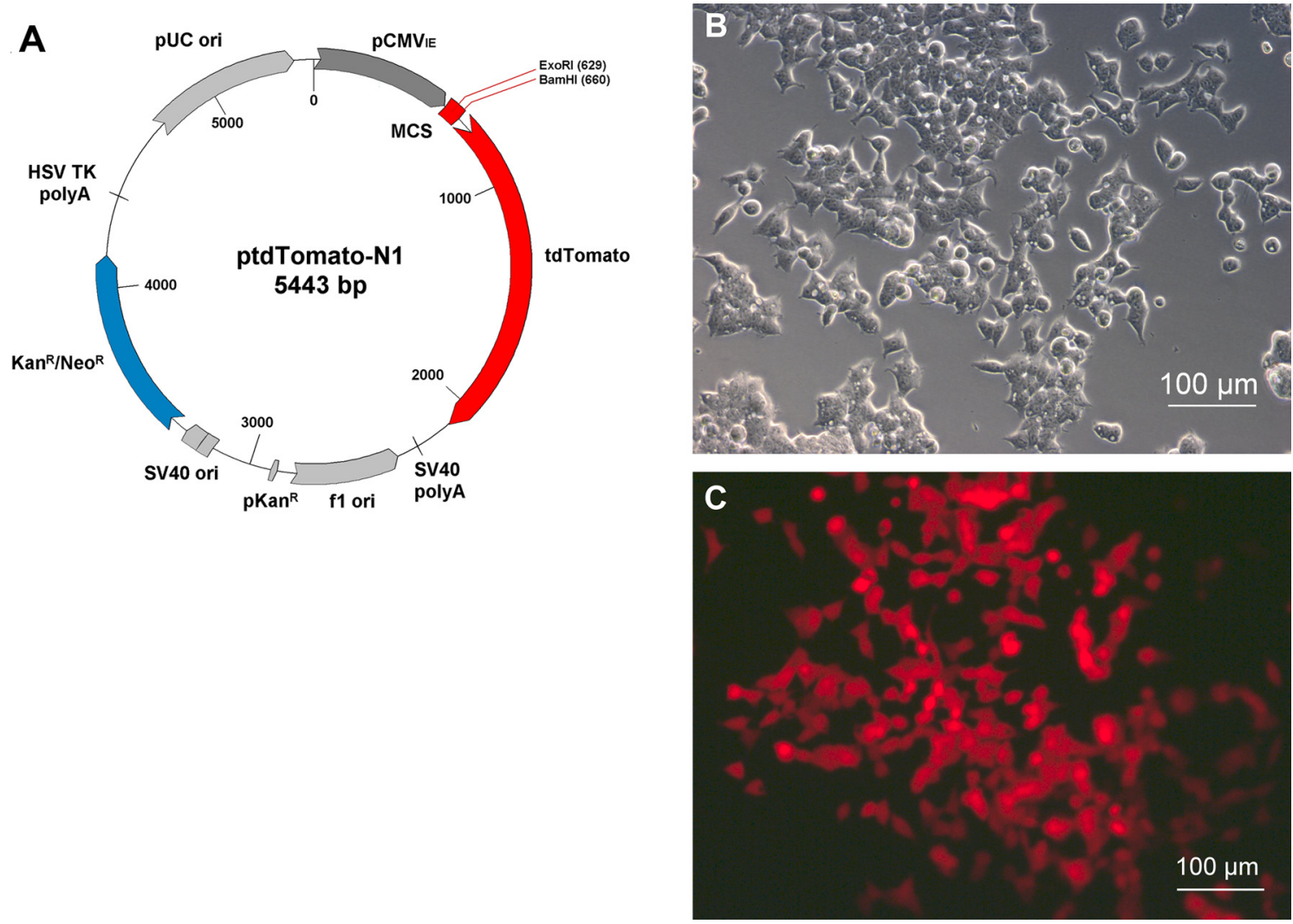

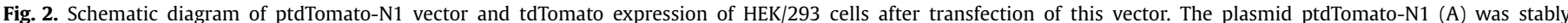

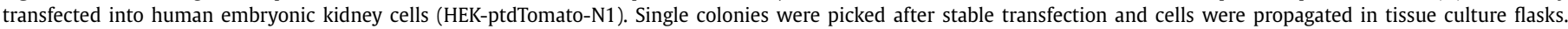
Photographs were taken with the microscopy camera Mrc 5 attached to a fluorescence microscope (B: phase contrast, C: red fluorescence, filter combination 540/590).

time is very restricted and it was not possible to repeat the experiments in independent beam times for every ion analyzed in this work. Means and standard errors were calculated with Microsoft ${ }^{\circledR}$ Office Excel 2010 and SigmaPlot 12.0.

\section{Results}

\subsection{Creation of stably transfected, tdTomato expressing cell lines}

HEK/293 cells were stably transfected with the ptdTomato-N1 vector containing the tdTomato gene under control of the CMV promoter (Fig. 2A). Stably transfected clones were screened for tdTomato protein fluorescence by fluorescence microscopy (Fig. 2B, C). All cells in a colony of stably transfected HEK/293 cells showed red fluorescence after cultivation in $\alpha$-medium containing G418. tdTomato was localized in the cytoplasm and the nucleus of the cell (Fig. 2C). Clones that expressed the tdTomato gene were expanded and analyzed by flow cytometry. This analysis of 26 HEKptdTomato-N1 clones indicated that clone \# 8 exhibited tdTomato expression in all cells and showed highest mean fluorescence (Fig. 3). Therefore HEK-ptdTomato-N1 clone \# 8 was selected for further experiments.

\subsection{Fluorescence spectra and intensity}

The excitation and emission spectra of tdTomato, expressed in HEK/293 cells, were determined using a spectrofluorimeter (Fig. 4). In the HEK-ptdTomato-N1 cells, the excitation spectrum peaks at $555 \mathrm{~nm}$ (fluorescence intensity, FI: 91.4). The emission spectrum shows its maximum at $577 \mathrm{~nm}$ (FI: 88.2). Excitation and emission maxima are rather near to each other with a Stokes shift (excitation/emission wavelength difference) of $22 \mathrm{~nm}$.
The tdTomato fluorescence of HEK and HEK-ptdTomato-N1 cells was analyzed by flow cytometry. Wild-type HEK cells showed low autofluorescence and were quantified using the tdTomato ${ }^{(-)}$ marker. Cells with a strong red fluorescence were designated as tdTomato $^{(+)}$(Fig. 5A). HEK-ptdTomato-N1 cells had superior fluorescence compared to formerly generated HEK-pEGFP-N1 cells (Fig. 5B).

\subsection{Growth of tdTomato expressing cells using fluorescence measurement}

In order to exclude possible effects of stable transfection on growth characteristics, the growth kinetics of HEK-ptdTomato-N1 cells was compared to those of HEK/293 cells. The growth curves showed a lag phase, an exponential phase (log phase) and a steady-state phase (Fig. 6A). The lag phases of both cell lines last for around $24 \mathrm{~h}$ after seeding, and then cells start growing exponentially with a comparable slope up to $120 \mathrm{~h}$. The doubling time of both cell lines during the log phase was $\sim 20 \mathrm{~h}$. The steady state is reached after $120 \mathrm{~h}$. The cells reach a maximum density of $4 \times 10^{5}$ cells $/ \mathrm{cm}^{2}$.

Cellular proliferation was monitored by measuring fluorescence intensity of constitutively expressed tdTomato. To calculate solely the fluorescence derived by fluorescence proteins, nontransfected HEK/293 cells were treated and measured the same way as the HEK-ptdTomato-N1 8 cells. The background fluorescence (average autofluorescence of HEK cells and the fluorescence of well bottom and the cell culture medium) was subtracted from the fluorescence values measured for HEK-tdTomato-N1 8 cells. Growth kinetics of HEK-tdTomato-N1 8 cells was determined by seeding $1 \times 10^{3}$ cells per well in a microtiter plate and measuring fluorescence intensities in the microplate reader daily. It was observed that cells started to be overcrowded after 10 days and fluorescence reached 

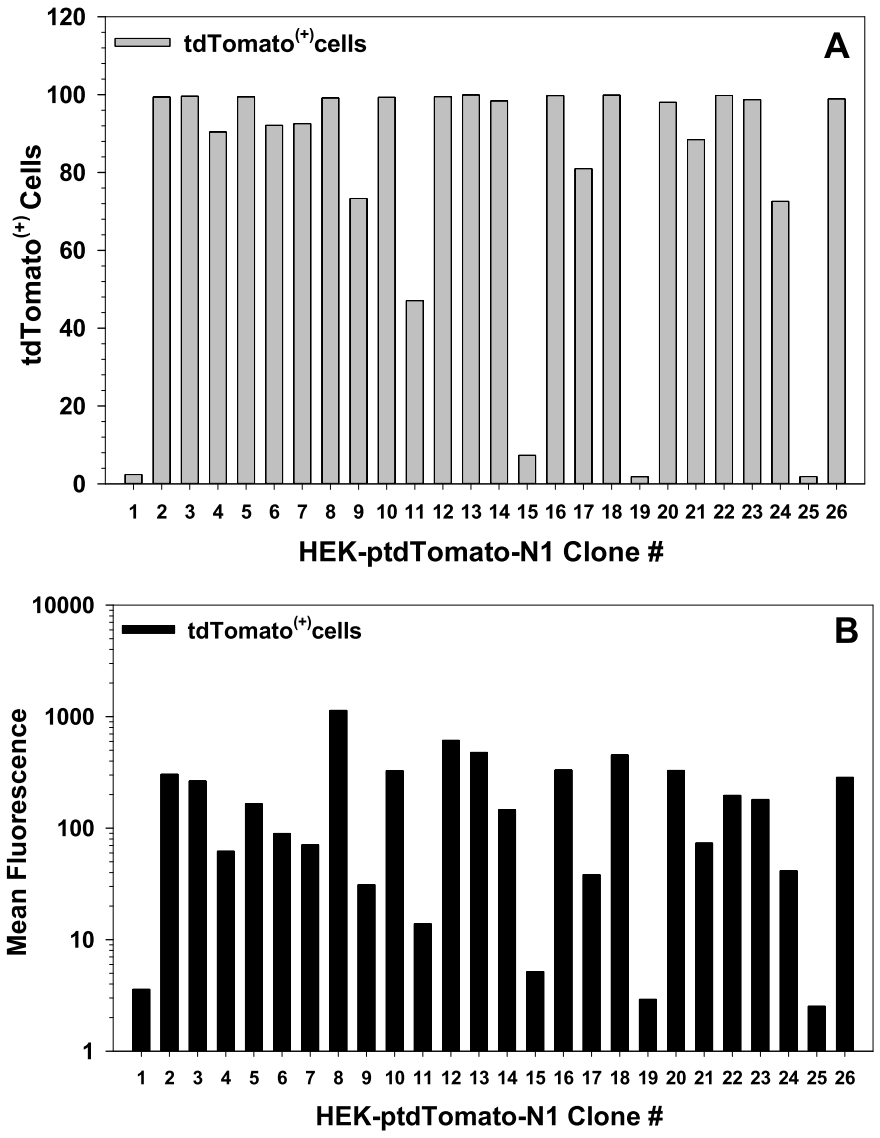

Fig. 3. tdTomato expression of stably transfected HEK cell clones. Clones were selected according to their percentage of the total population expressing the fluorescent protein tdTomato (A) and their mean fluorescence (B). Clone \# 1 represents the untransfected wild-type cells (HEK/293). Clone \# 8 showed highest mean fluorescence and was selected for further experiments.

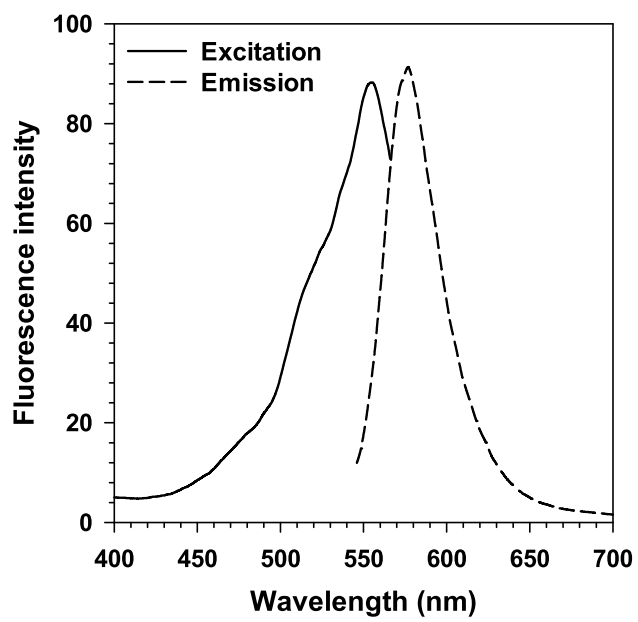

Fig. 4. Fluorescence spectra of tdTomato in HEK cells. The tdTomato protein was stably and constitutively expressed in HEK/293 cells. For measurement of the emission spectrum of tdTomato (A), the excitation wavelength was set to $510 \mathrm{~nm}$. The excitation spectrum of tdTomato was measured at an emission of $610 \mathrm{~nm}$.

a plateau after 12 days (Fig. 6B). Measurement of fluorescence intensities of known cell numbers in the microplate reader revealed that the red fluorescence augmented as the cell count per well increased (Fig. 7). Thereby, the cell number can be determined from the respective fluorescence intensity values using this fluorescence intensity-cell number curve (Fig. 7).

\subsection{Growth inhibition after X-ray exposure}

Cells were exposed to X-rays (0, 2, 6 and $12 \mathrm{~Gy}) 48 \mathrm{~h}$ after seeding. The fluorescence intensity was measured subsequently twice a day over $\sim 100 \mathrm{~h}$ in the microplate reader. It was observed that the increase of relative fluorescence intensity over time was reduced with increasing dose (Fig. 8A). The relative cellular proliferation decreased significantly after $2 \mathrm{~Gy}$ and proliferation was strongly suppressed after exposure to $16 \mathrm{~Gy}$. The growth curves after neon ion exposure also show a reduced growth after exposure to $2 \mathrm{~Gy}$ (Fig. 8B). The growth inhibiting effect of $6 \mathrm{~Gy}$ neon ions is stronger compared to $6 \mathrm{~Gy} \mathrm{X}$-irradiation. The results show that the applied recombinant cell line is suitable for screening the cytotoxic effect of different radiation qualities including heavy ions.

\subsection{Cellular survival after heavy ions exposure}

Relative fluorescence was calculated to compare the effect of different radiation qualities on cellular proliferation (Fig. 9A). Survival decreased with increasing dose. High LET radiation including ${ }^{13} \mathrm{C}(33 \mathrm{keV} / \mu \mathrm{m}),{ }^{22} \mathrm{Ne}(91 \mathrm{keV} / \mu \mathrm{m}),{ }^{56} \mathrm{Fe}(151 \mathrm{keV} / \mu \mathrm{m}),{ }^{64} \mathrm{Ni}$ $(175 \mathrm{keV} / \mu \mathrm{m})$ and ${ }^{58} \mathrm{Ni}(905 \mathrm{keV} / \mu \mathrm{m})$ ions showed a high damaging capacity as seen by the steep decrease of relative fluorescence. The slope of the curves represents the killing effect which depends on the radiation quality as defined by LET. Heavy ions in the LET range of $\sim 30-175 \mathrm{keV} / \mu \mathrm{m}$ showed a maximal killing effect. In case of ${ }^{58} \mathrm{Ni}$ particles with very high LET $(905 \mathrm{keV} / \mu \mathrm{m})$, the killing effect was only slightly stronger compared to X-rays.

The RBE for growth reduction was calculated based on the dose needed to reduce cell growth to $50 \%$ with $200 \mathrm{kV} \mathrm{X-rays} \mathrm{as} \mathrm{refer-}$ ence radiation (Fig. 9B). The $\mathrm{RBE}_{50 \% \mathrm{PR}}$ reaches a maximum of 4.3 at $91 \mathrm{keV} / \mu \mathrm{m}$ for ${ }^{22} \mathrm{Ne}$ ions. The $\mathrm{RBE}_{50 \% \mathrm{PR}}$ is well above 2 for ${ }^{13} \mathrm{C}$, ${ }^{56} \mathrm{Fe}$ and ${ }^{64} \mathrm{Ni}$ ions. It drops to 1.4 for ${ }^{58} \mathrm{Ni}$ ions with an LET of $905 \mathrm{keV} / \mu \mathrm{m}$.

\section{Discussion}

In the last few decades bacterial, yeast, insect and mammalian cell-based systems have been developed (Baumstark-Khan et al., 2010; Lai et al., 2006; Roberto et al., 2002; Lagendijk et al., 2010) as a low cost and efficient alternative assays to live animals. For the purpose of radiobiological studies, a human cell line suitable to be transfected with a fluorescent reporter gene was selected. HEK cells are considered as a useful tool to study different cellular processes, as they can be easily transiently and stably transfected. HEK cells have already been used in pharmacological, endocrinological, and toxicological studies and also in other reporter gene studies (Sung et al., 2009; Lodeiro et al., 2009; Lau et al., 2009; Bora et al., 2008; Mao et al., 2007). HEK cells have also been used in radiobiological studies as a biological model for dose-depth distribution of a proton beam using the resazurin assay (Kim et al., 2007) and for analysis of cell cycle checkpoints after irradiation (Yu et al., 2001). In our previous studies with HEK cells, the LET dependence of cellular killing by heavy ions was comparable to that observed in other cell types (Hellweg et al., 2011).

Fluorescent proteins have revolutionized cell biology because they can be genetically encoded, targeted to specific sites into the cell or tissues and can be imaged repeatedly in living systems. Choosing a suitable fluorescent protein with higher fluorescence intensity and stability for reporter assays was a critical issue which was done by comparing the expression of the fluorescent proteins EGFP and tdTomato in HEK/293 cells. As tdTomato has the highest brightness and is exceptionally photostable, it was chosen for constructing a new HEK/293 based reporter assay for cytotoxic effects of ionizing radiation. 

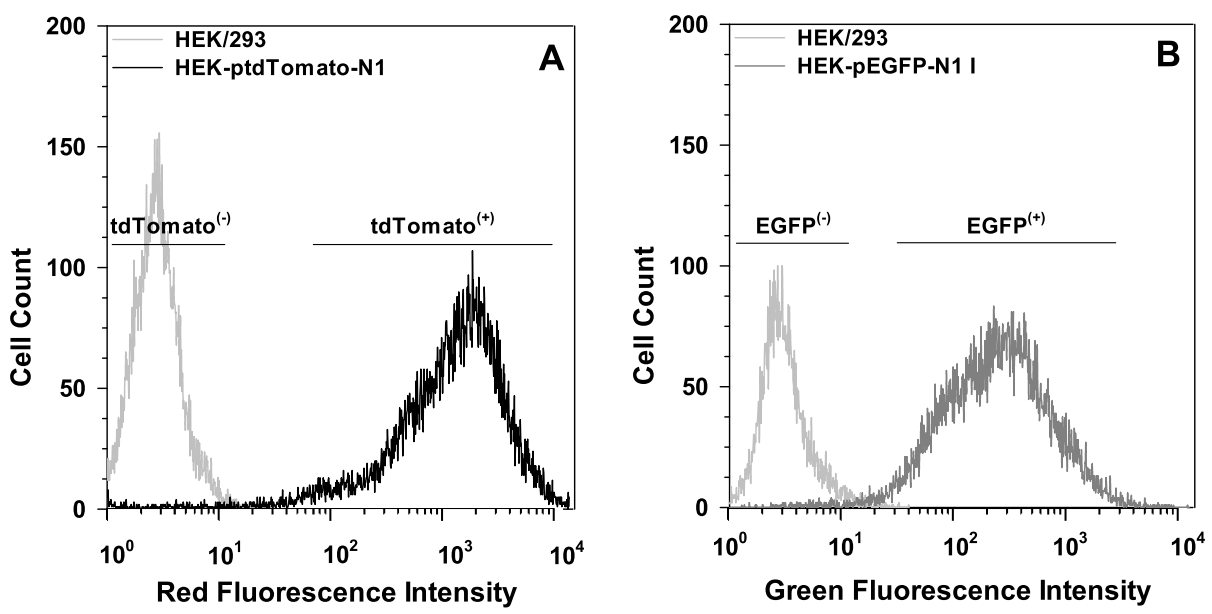

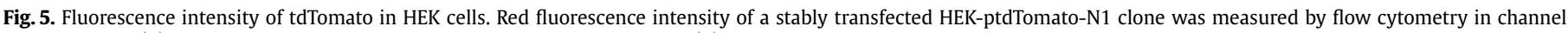

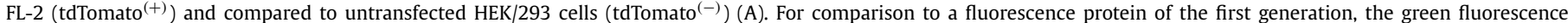

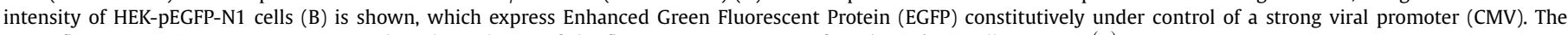
green fluorescence intensity was measured in channel FL-1 of the flow cytometer. Untransfected HEK/293 cells are EGFP(-).
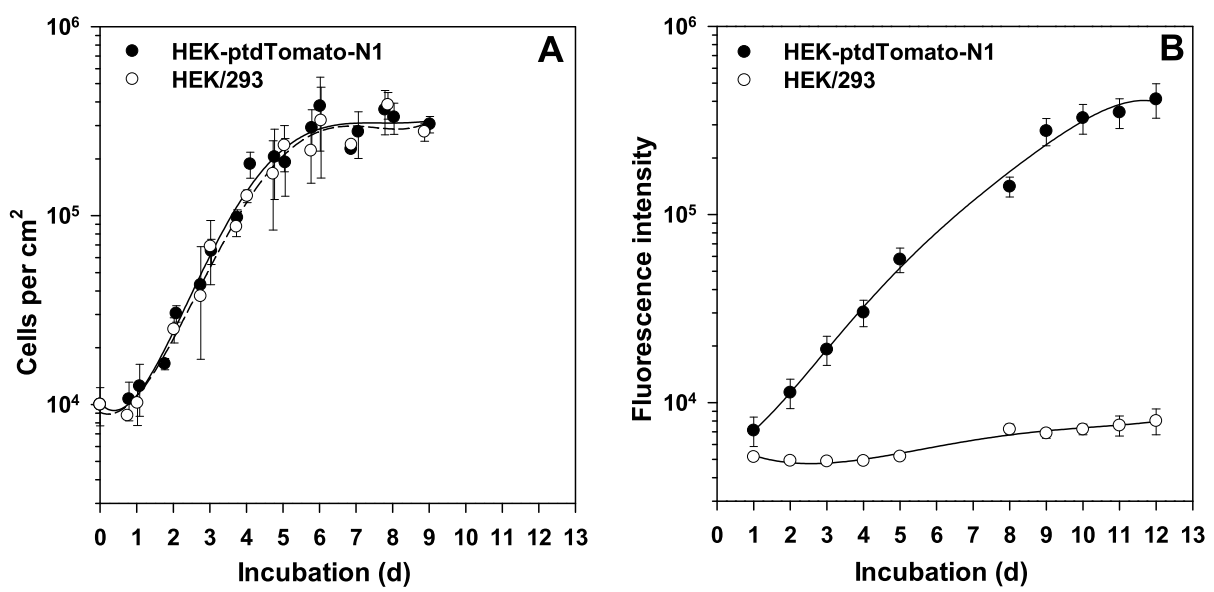

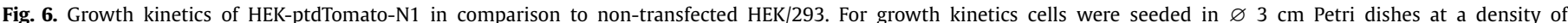

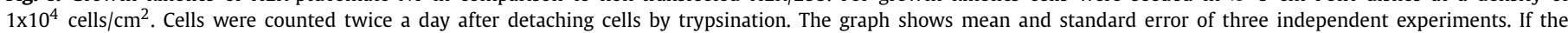

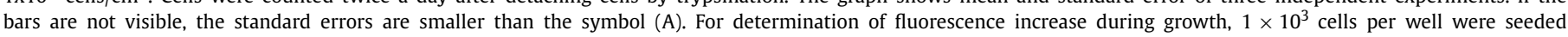

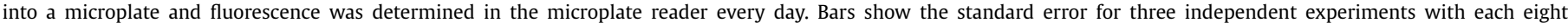
replicates (B).

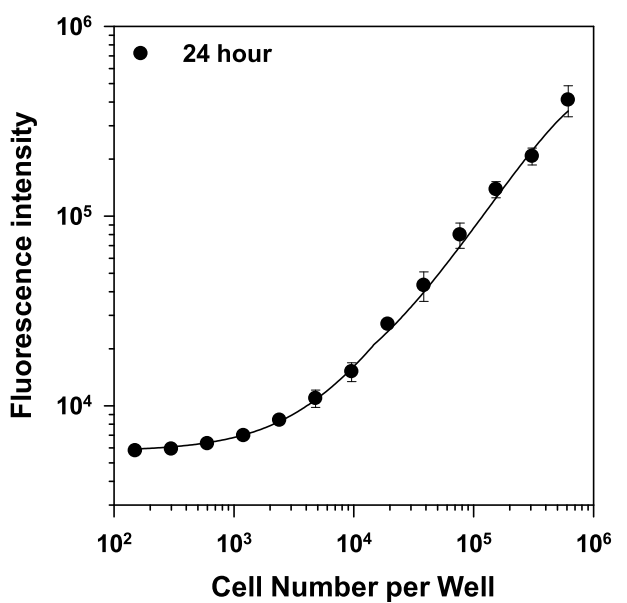

Fig. 7. Fluorescence intensity of HEK-ptdTomato-N1 cell layers depends on cell number. The cells were seeded in increasing cell numbers into microtiter plates and fluorescence intensity of living cells was measured in the microplate reader $24 \mathrm{~h}$ after seeding. Bars show the standard error for three independent experiments with each 4 replicates.

\subsection{Preparation of stably transfected, tdTomato expressing cell lines}

In order to save time and to minimize the experiment variability, HEK/293 cells were stably transfected with the ptdTomato-N1 vector. A drawback of stable transfection is that expression of the fluorescent protein is affected by the gene integration site and the number of integrated gene copies. In some of the clones expression of fluorescent protein was low which might be due to the integration into an inactive part of a chromosome. The tdTomato expressing clones were expanded in presence of G418 after identification with the fluorescence microscope. Some of the clones did not survive in presence of G418 as cellular enzymes might destroy the promoter or the aminoglycoside phosphotransferase gene. Therefore, preparation of a suitable stable cell line required screening of multiple clones that survived in presence of G418. Clone \# 8 stably integrated the foreign DNA into its genome, survived the selection by the antibiotic G418 and showed the highest mean fluorescence; therefore it was selected for further experiments.

\subsection{Fluorescence spectra of tdTomato expressing cells}

In the HEK-ptdTomato-N1 cell line, the fluorescence excitation and emission spectra of tdTomato were determined by spec- 

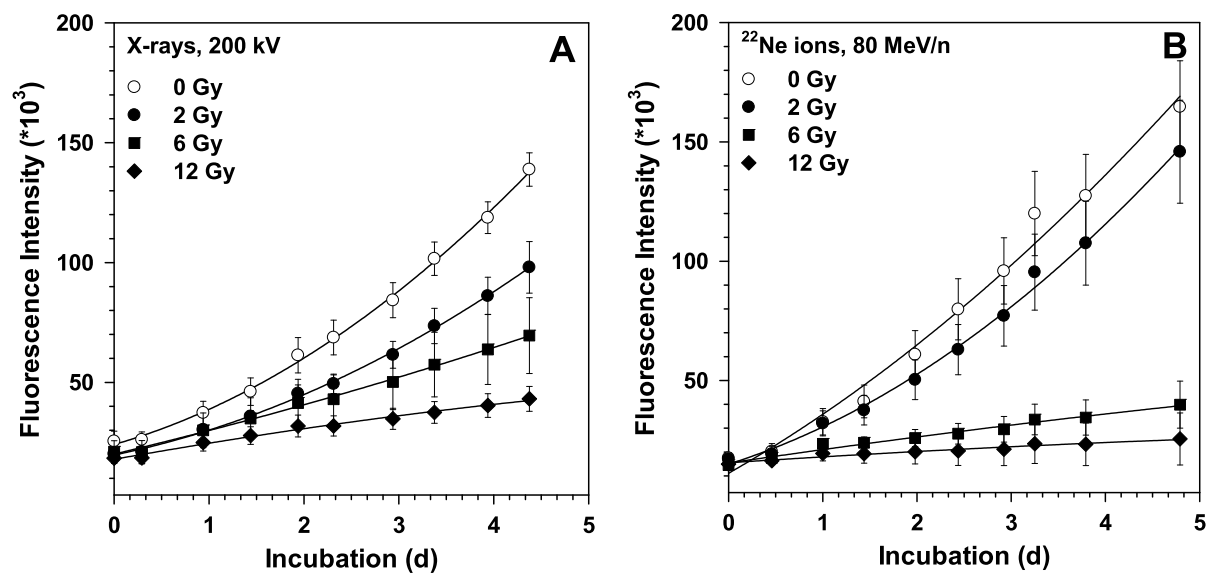

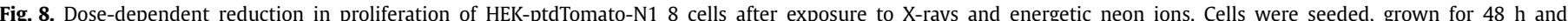

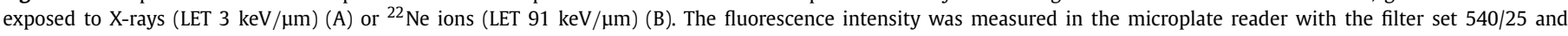
$590 / 35$ twice a day over $115 \mathrm{~h}$.
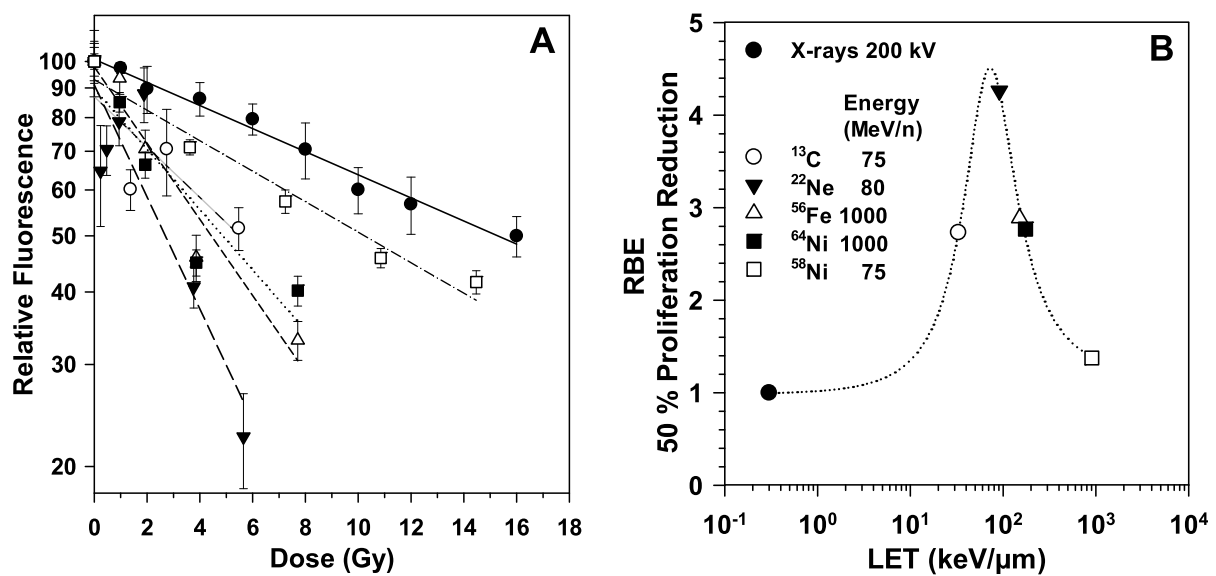

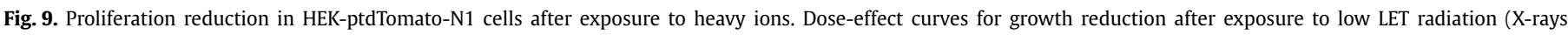

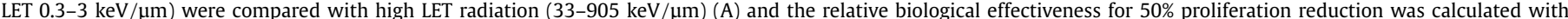

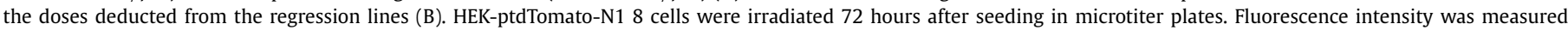

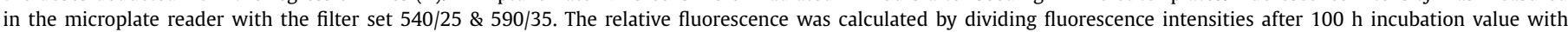

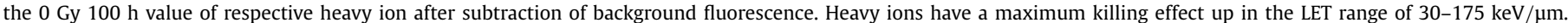

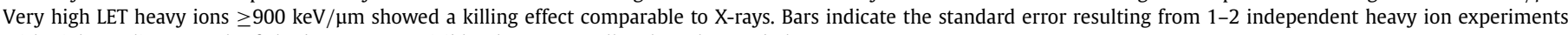
with eight replicates each. If the bars are not visible, they are smaller than the symbol.

trofluorimetry which describes the relationship between absorbed and emitted photons at specified wavelengths (Lakowicz, 1999). tdTomato has detectable emission intensity for a broad excitation range ( $\sim 500-580 \mathrm{~nm})$. Maximum emission was achieved for the excitation wavelength of $555 \mathrm{~nm}$. When excited at $555 \mathrm{~nm}$, the maximum emission occurs at $577 \mathrm{~nm}$. In literature, the excitation and emission maxima of tdTomato were reported to be at $554 / 581 \mathrm{~nm}$ and a filter set of 535/20 and 615/100 for excitation and emission was recommended respectively for minimizing crosstalk with other fluorescent proteins and better spectral separation (Shaner et al., 2005). The very minor differences in the maxima between our finding and literature might be explained by the width of the tip of the peak stretching over several nanometers.

\subsection{Fluorescence intensity of tdTomato expressing cells}

Flow cytometric analysis of HEK-ptdTomato-N1 8 cells revealed a strong tdTomato expression of the whole cell population. The mean fluorescence output of HEK-ptdTomato-N1 8 cells is about 1000 times higher compared to non-transfected cells. The single peak in the red fluorescence histogram confirms HEK-ptdTomato-
N1 8 to be a stable cell line with all the cells constitutively expressing the red fluorescent protein tdTomato. The fluorescence intensity of non-transfected HEK cells remained between 0 and 10 which was defined as the autofluorescence range (tdTomato $\left.{ }^{(-)}\right)$. The fluorescent proteins EGFP and tdTomato have different physical and optical properties (Shaner et al., 2008). The extinction coefficient and quantum yield of tdTomato are much higher than for EGFP $\left(138,000 \mathrm{Mol}^{-1} \mathrm{~cm}^{-1}\right.$ versus $56,000 \mathrm{Mol}^{-1} \mathrm{~cm}^{-1}$, and 0.69 versus 0.60 , respectively) (Shaner et al., 2004). In this study it was noticed that, compared to HEK-pEGFP-N1 cells, the mean fluorescence intensity of HEK-ptdTomato-N1 8 cells was $\sim 6$ times higher.

\subsection{Growth of tdTomato expressing cells}

The growth curves of both HEK/293 and HEK-ptdTomato-N1 8 cells show three phases of cell growth: the lag phase, log phase and stationary phase. Both cell lines showed no significant differences in growth patterns. The stably transfected reporter plasmid did obviously not affect growth regulating genes. The newly constructed reporter system HEK-ptdTomato-N1 is ready for further experiments. 


\subsection{Fluorescence measurement for growth determination}

The tdTomato fluorescence measurement allows a rapid estimation of cell growth instead of counting cells. The tdTomato fluorescence is linked to total cellular protein content due to its intracellular expression. It can also be detected in living cells by measuring fluorescence intensity in a microplate reader. In the microplate, red fluorescence increased as HEK-ptdTomato-N1 8 cells started dividing. The tdTomato protein expression increased exponentially with cell number in the log phase. In the stationary phase when the cell count reached the maximum after 7 days, fluorescence was still increasing due to ongoing protein synthesis till 10 days. After 10 days, cells started to be overcrowded in the wells of a 96-well plate and fluorescence reached a plateau.

To correlate fluorescence intensity and cell number, defined cell numbers were seeded. After attachment of the cells and prior to the start of cell division 24 hours after seeding, fluorescence intensity was determined in the microplate reader. The minimum number of cells that gives detectable fluorescence is above 2400 cells per well, below this cell count the microplate reader was unable to distinguish HEK-ptdTomato-N1 8 cells fluorescence from background fluorescence of microplate and cell culture medium. The starting cell number of 3000 cells per well for proliferation assays was well above the detection threshold, allowing growth determination measurements starting immediately after attachment of cells to the well bottom.

\subsection{Growth inhibition after X-ray exposure}

Ionizing radiation (X-rays and heavy ions) is cytotoxic to the cells and inhibits cellular growth. The growth after radiation exposure was monitored by fluorescence measurement of tdTomato content of the cell layer in a microplate. The tdTomato fluorescence represents the cellular fluorescent protein content which was evaluated as endpoint for cytotoxicity. The cytotoxic effect of $\mathrm{X}$-rays was investigated by measuring the fluorescence of the cell layer twice a day in a microplate reader. After X-irradiation, the tdTomato fluorescence increase was delayed because X-rays inhibit proliferation due to its cytotoxic and genotoxic nature and effects on cell cycle progression. The growth pattern of X-irradiated cells showed a dose-response relationship. At lower doses ( $\leq 4 \mathrm{~Gy}$ ), cells stayed in lag phase up to 36 hours but grew exponentially afterwards. Higher doses ( $\geq 4 \mathrm{~Gy}$ ) inhibited cellular growth due to higher cytotoxic effects. This cytotoxicity bioassay is related to proliferation assays which measure growth of a cell population based on cellular protein content (Hellweg et al., 2007a; Skehan et al., 1990). In a previous study, loss of fluorescence following low temperature exposure was explored as an indicator of cell death (Elliott et al., 2000). Fluorescence signals represent different processes which contribute to increased cellular protein content: (i) cell division, which results in new protein synthesis in the daughter cells and (ii) continued protein synthesis of cells in the interphase or during a cell cycle arrest. Direct effects of ionizing radiation on tdTomato are expected to be of negligible importance for two reasons. First, the test is predicated on the tdTomato that is newly synthesized after radiation exposure and not on the tdTomato that is present in the cell during irradiation. So even if there is radiation damage to tdTomato, it will not affect the fluorescence measured $100 \mathrm{~h}$ after radiation exposure. Second, the protein damage including that inflicted to tdTomato by ionizing radiation exposure is expected to be extremely low in the dose range under investigation, as protein damage studies are usually carried out in the kGy dose range (Vuckovic et al., 2005). The sensitivity of fluorescent protein based cytotoxicity bioassays were proven to be higher compared to other assays such as the MTT test (Hellweg et al., 2007a).

\subsection{Cellular survival after heavy ions exposure}

In this study, the effect of accelerated heavy ions on proliferation of human cells was investigated. For this purpose, HEK-

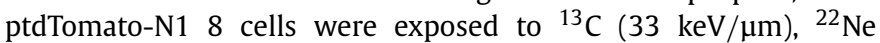
$(91 \mathrm{keV} / \mu \mathrm{m}),{ }^{56} \mathrm{Fe}(151 \mathrm{keV} / \mu \mathrm{m}),{ }^{64} \mathrm{Ni}(175 \mathrm{keV} / \mu \mathrm{m})$ and ${ }^{58} \mathrm{Ni}$ ions (905 keV/ $\mu \mathrm{m}$ ). To compare the biological impact of different heavy ions and X-rays, the observed level of tdTomato fluorescence was normalized for each radiation quality. Relative fluorescence 100 hours after irradiation as a measure of the cytotoxic radiation effect decreased with increasing doses and LET values. As dose and LET of ionizing radiation augment, the ability to produce biological damages also increases (Suntharalingam et al., 2005). The slope of the curves depends on the radiation quality (LET).

Heavy ions showed a maximum killing effect at an LET of 91 $\mathrm{keV} / \mu \mathrm{m}$. Very high LET heavy ions $(\geq 900 \mathrm{keV} / \mu \mathrm{m})$ showed a lower killing effect compared to ${ }^{13} \mathrm{C},{ }^{22} \mathrm{Ne},{ }^{56} \mathrm{Fe}$ and ${ }^{64} \mathrm{Ni}$ ions in the LET range of 33 to $175 \mathrm{keV} / \mu \mathrm{m}$, probably due to compacted ionizations within a very narrow track structure with extremely high dose deposition in a small volume with an increasing number of unhit cells, resulting in an overkill effect and lower cell killing potential for the irradiated cell population. Based on fluence, the cell killing effect at very high LET $(\geq 900 \mathrm{keV} / \mu \mathrm{m})$ is less prominent and least efficient in reducing cellular survival (Hellweg et al., 2011). It was concluded that cell killing caused by heavy ions depends on the ion type, energy and the LET value. TdTomato is expressed constitutively and accumulates only in living cells. After irradiation a dying tdTomato expressing cell does not contribute to the fluorescence increase anymore. The reduced fluorescence might be due to the fact that tdTomato protein is soluble (Shaner et al., 2005), leaks out of the dead cells and is removed by regular medium changes. The growth test using tdTomato allows a better estimation of the fraction of residual replicative cells after radiation exposure compared to other short-term cytotoxicity tests such as the MTT test. Because tetrazolium salt based assays destroy the cells, time-course experiments cannot be carried out (Rampersad, 2012). Furthermore, the reducing potential resulting in conversion of the MTT reagent to the colored formazan product depends on cell type, resulting in cell-type specific calibration curves of optical density and number of cells (Mosmann, 1983; Alley et al., 1988). In other than radiobiological applications, the MTT test reagents might also interact with tested compounds or multidrug resistance (MDR) protein, that is often expressed in tumor cells, leading to false positive or false negative results (Vellonen et al., 2004; Worle-Knirsch et al., 2006).

Compared to the standard radiobiological test for survival, the colony forming ability test, the sensitivity of the fluorescent proteins based growth test is lower, but this assay requires much less time and material (Hellweg et al., 2007a) and as such the test is more cost-effective.

The proliferation test proved to be useful to determine biological effectiveness of heavy ions of different LET values. RBE is highly relevant information for radiation protection and radiotherapy. The RBE for reduction of cell proliferation of $50 \%$ was dependent on LET - RBE increases to a maximum and decreases subsequently. In this research work, it has been determined that maximum biological efficiency lies in the range of $\sim 30$ to $175 \mathrm{keV} / \mu \mathrm{m}$ and peaks around $90 \mathrm{keV} / \mu \mathrm{m}$. For a wide range of mammalian cells including HEK cells, the RBE for cell killing reaches its maximum in this LET range (Antonovic et al., 2013; Hellweg et al., 2007b; $\mathrm{Hu}$ et al., 2014). At $100 \mathrm{keV} / \mu \mathrm{m}$, average separation density between ionizing events from single hits roughly coincides with the DNA double helix diameter, i.e., $2 \mathrm{~nm}(20 \AA)$ and has the greatest probability of causing a double-strand break which is the basis for most biologic effects (Hall and Hei, 2003). This study also confirms 
the findings of Stoll et al. $(1995,1996)$ who found an RBE for cell survival by high LET nickel ions $(>1000 \mathrm{keV} / \mu \mathrm{m})$ around 1 .

\section{Conclusions}

In order to measure cytotoxic effects, the fluorescent protein tdTomato is a very useful reporter protein as it is more stable than other fluorescent proteins. The fluorescence intensity of tdTomato in stably transfected cells is around 6 times higher than that of EGFP. tdTomato fluorescence can easily be measured in microplates using a fluorescence microplate reader equipped with appropriate filter sets or monochromators. HEK-ptdTomato-N1 8 cells can be used for estimation of the fraction of residual replicative cells after radiation exposure. Compared to the standard radiobiological test for survival, the colony forming ability assay, the ease of performance of the tdTomato proliferation test allows screening of a large variety of cytotoxic conditions in a labor-, time- and moneysaving manner, and it requires irradiation of only a very small sample area. The HEK-ptdTomato-N1 reporter system gives also strong signals when measured by flow cytometry, which allows single cell analysis. Automated image analysis of fluorescence microscopic images could give more details about radiation-induced cytotoxicity in mammalian cells. Therefore, the constitutively expressed tdTomato is a suitable reporter of radiation induced growth reduction of human cells. HEK-ptdTomato-N1 8 cells can be also used for monitoring of other cytotoxic agents than radiation and subsequent risk estimation. After these ground based preparatory tests, the biosensor system will be used to reduce uncertainties in risk assessment of space environmental factors such as space radiation and microgravity. The space experiment Cellular Responses to Radiation in Space (CELLRAD), selected by NASA/ESA to be performed on the ISS, will supply basic information on the cellular response to radiation, including proliferation reduction, applied in microgravity. Preparatory tests for this space experiment including test of upload and storage conditions are currently performed. Furthermore, it can be applied to rapidly monitor the effect of shielding measures on cellular survival behind the shielding material, and to determine a biological weighted depth dose distribution in a human phantom.

\section{Conflict of interest statement}

The authors declare that they have no conflict of interest.

\section{Acknowledgements}

Arif A. Chishti received a scholarship of the Helmholtz Space Life Sciences Research School (SpaceLife) which is funded by the Helmholtz Association (Helmholtz-Gemeinschaft VO-KH-300) and the German Aerospace Center (Deutsches Zentrum für Luft- und Raumfahrt e.V., DLR). Part of this work was funded by the European Commission in the frame of the FP7 HAMLET project (Project \# 218817). Beamtimes at GSI were supported by the European Space Agency (ESA) program "Investigations into Biological Effects of Radiation Using the GSI Accelerator Facility" (Ground based radiation field simulation of the MATROSHKA experiment: Physical and Biological Experiments for Radiation Risk Assessment - AO-08-IBER-12 and AO-10-IBER). The authors would like to thank the staff at the heavy ions accelerator facilities at the Centre Interdisciplinaire de Recherche Ions Lasers (CIRIL) at GANIL, Caen, France, and GSI Helmholtzzentrum für Schwerionenforschung GmbH, Darmstadt, Germany, for dosimetry and support of the heavy ion experiments, especially Dr. Isabelle Testard, Florent Durantel (GANIL), Chiara La Tessa, Dieter Schardt and Michael Scholz (GSI), and all the members of the Biodiagnostics group at DLR for their help during beam times.

\section{References}

Alley, M.C., Scudiero, D.A., Monks, A., Hursey, M.L., Czerwinski, M.J., Fine, D.L., Abbott, B.J., Mayo, J.G., Shoemaker, R.H., Boyd, M.R., 1988. Feasibility of drug screening with panels of human tumor cell lines using a microculture tetrazolium assay. Cancer Res. 48, 589-601.

Antonovic, L., Brahme, A., Furusawa, Y., Toma-Dasu, I., 2013. Radiobiological description of the LET dependence of the cell survival of oxic and anoxic cells irradiated by carbon ions. J. Radiat. Res. 54, 18-26.

Baumstark-Khan, C., Hellweg, C.E., Reitz, G., 2010. Cytotoxicity and genotoxicity reporter systems based on the use of mammalian cells. Adv. Biochem. Eng. Biotechnol. 118, 113-151.

Berger, T., Bilski, P., Hajek, M., Puchalska, M., Reitz, G., 2013. The MATROSHKA experiment: results and comparison from extravehicular activity (MTR-1) and intravehicular activity (MTR-2A/2B) exposure. Radiat. Res. 180, 622-637.

Berridge, M.V., Herst, P.M., Tan, A.S., 2005. Tetrazolium dyes as tools in cell biology: new insights into their cellular reduction. Biotechnol. Annu. Rev. 11, 127-152.

Bora, R.S., Gupta, D., Malik, R., Chachra, S., Sharma, P., Saini, K.S., 2008. Development of a cell-based assay for screening of phosphodiesterase 10A (PDE10A) inhibitors using a stable recombinant HEK-293 cell line expressing high levels of PDE10A. Biotechnol. Appl. Biochem. 49, 129-134.

Campbell, R.E., 2002. A monomeric red fluorescent protein. Proc. Natl. Acad. Sci. USA 99, 7877-7882.

Cucinotta, F.A., Durante, M., 2006. Cancer risk from exposure to galactic cosmic rays: implications for space exploration by human beings. Lancet Oncol. 7, 431-435.

Davidson, M.W., Campbell, R.E., 2009. Engineered fluorescent proteins: innovations and applications. Nat. Methods 6, 713-717.

Elliott, G., McGrath, J., Crockett-Torabi, E., 2000. Green fluorescent protein: a novel viability assay for cryobiological applications. Cryobiology 40, 360-369.

Hall, E.J., Hei, T.K., 2003. Genomic instability and bystander effects induced by highLET radiation. Oncogene 22, 7034-7042.

Hellweg, C.E., Arenz, A., Baumstark-Khan, C., 2007a. Assessment of space environmental factors by cytotoxicity bioassays. Acta Astronaut. 60, 525-533.

Hellweg, C.E., Baumstark-Khan, C., Schmitz, C., Lau, P., Meier, M.M., Testard, I., Berger T., Reitz, G., 2011. Activation of the nuclear factor $\kappa \mathrm{B}$ pathway by heavy ion beams of different linear energy transfer. Int. J. Radiat. Biol. 87, 954-963.

Hellweg, C.E., Bogner, S., Spitta, L., Arenz, A., Baumstark-Khan, C., 2007b. Transcriptional response of human cells to microbeam irradiation with $2.1 \mathrm{MeV}$ alpha particles. Adv. Space Res. 39, 1056-1065.

Hendriks, G., Atallah, M., Raamsman, M., Morolli, B., van der Putten, H., Jaadar, H. Tijdens, I., Esveldt-van Lange, R., Mullenders, L., van de Water, B., Vrieling, H., 2011. Sensitive DsRed fluorescence-based reporter cell systems for genotoxicity and oxidative stress assessment. Mutat. Res. 709-710, 49-59.

Hinterdorfer, P., van Oijen, A., 2009. Handbook of Single-Molecule Biophysics. Springer Science Business Media, LLC, New York.

Hoffman, R.M., 2005. The multiple uses of fluorescent proteins to visualize cancer in vivo. Nat. Rev. Cancer 5, 796-806.

Horneck, G., Klaus, D.M., Mancinelli, R.L., 2010. Space microbiology. Microbiol. Mol. Biol. Rev. 74, 121-156.

Hu, Y., Hellweg, C.E., Baumstark-Khan, C., Reitz, G., Lau, P., 2014. Cell cycle delay in murine pre-osteoblasts is more pronounced after exposure to high-LET compared to low-LET radiation. Radiat. Environ. Biophys. 53, 73-81.

Jiang, X., Coffino, P., Li, X., 2004. Development of a method for screening short-lived proteins using green fluorescent protein. Genome Biol. 5, R81.

Kim, M.J., Pal, S., Tak, Y.K., Lee, K.H., Yang, T.K., Lee, S.J., Song, J.M., 2007. Determination of the dose-depth distribution of proton beam using resazurin assay in vitro and diode laser-induced fluorescence detection. Anal. Chim. Acta 593, 214-223.

Lagendijk, E.L., Validov, S., Lamers, G.E., Weert, S., Bloemberg, G.V., 2010. Genetic tools for tagging Gram-negative bacteria with mCherry for visualization in vitro and in natural habitats, biofilm and pathogenicity studies. FEMS Microbiol. Lett. 305 (1), 81-90.

Lai, C., Jiang, X., Li, X., 2006. Development of luciferase reporter-based cell assays. Assay Drug Dev. Technol. 4, 307-315.

Lakowicz, J.R., 1999. Instrumentation for fluorescence spectroscopy. In: Principles of Fluorescence Spectroscopy. Springer US, pp. 25-61.

Lau, P.N., Chow, K.B., Chan, C.B., Cheng, C.H., Wise, H., 2009. The constitutive activity of the ghrelin receptor attenuates apoptosis via a protein kinase C-dependent pathway. Mol. Cell. Endocrinol. 299, 232-239.

Li, X., Zhang, G., Ngo, N., Zhao, X., Kain, S.R., Huang, C.C., 1997. Deletions of the Aequorea victoria green fluorescent protein define the minimal domain required for fluorescence. J. Biol. Chem. 272, 28545-28549.

Lodeiro, M., Theodoropoulou, M., Pardo, M., Casanueva, F.F., Camina, J.P., 2009 c-Src regulates Akt signaling in response to ghrelin via beta-arrestin signalingindependent and -dependent mechanisms. PLoS ONE 4, e4686.

Mao, W.P., Ye, J.L., Guan, Z.B., Zhao, J.M., Zhang, C., Zhang, N.N., Jiang, P., Tian, T., 2007. Cadmium induces apoptosis in human embryonic kidney (HEK) 293 cells by caspase-dependent and -independent pathways acting on mitochondria. Toxicol. in Vitro 21, 343-354. 
Mosmann, T., 1983. Rapid colorimetric assay for cellular growth and survival: application to proliferation and cytotoxicity assays. J. Immunol. Methods 65, 55-63.

Panganiban, R.A., Snow, A.L., Day, R.M., 2013. Mechanisms of radiation toxicity in transformed and non-transformed cells. Int. J. Mol. Sci. 14, 15931-15958.

Pettersen, E.O., Bjorhovde, I., Sovik, A., Edin, N.F., Zachar, V., Hole, E.O., Sandvik, J.A., Ebbesen, P., 2007. Response of chronic hypoxic cells to low dose-rate irradiation. Int. J. Radiat. Biol. 83, 331-345.

Puchalska, M., Bilski, P., Berger, T., Hajek, M., Horwacik, T., Korner, C., Olko, P., Shurshakov, V., Reitz, G., 2014. NUNDO: a numerical model of a human torso phantom and its application to effective dose equivalent calculations for astronauts at the ISS. Radiat. Environ. Biophys. 53, 719-727.

Rampersad, S.N., 2012. Multiple applications of Alamar Blue as an indicator of metabolic function and cellular health in cell viability bioassays. Sensors (Basel) 12, 12347-12360.

Reitz, G., 2008. Characteristic of the radiation field in low Earth orbit and in deep space. Z. Med. Phys. 18, 233-243.

Roberto, F.F., Barnes, J.M., Bruhn, D.F., 2002. Evaluation of a GFP reporter gene construct for environmental arsenic detection. Talanta 58, 181-188.

Shaner, N.C., Campbell, R.E., Steinbach, P.A., Ben Giepmans, N.G., Palmer, A.E., Tsien, R.Y., 2004. Improved monomeric red, orange and yellow fluorescent proteins derived from Discosoma sp. red fluorescent protein. Nat. Biotechnol. 22, 1567-1572.

Shaner, N.C., Lin, M.Z., McKeown, M.R., Steinbach, P.A., Hazelwood, K.L., Davidson, M.W., Tsien, R.Y., 2008. Improving the photostability of bright monomeric orange and red fluorescent proteins. Nat. Methods, 545-551.

Shaner, N.C., Steinbach, P.A., Tsien, R.Y., 2005. A guide to choosing fluorescent proteins. Nat. Methods 2, 905-909.

Skehan, P., Storeng, R., Scudiero, D., Monks, A., McMahon, J., Vistica, D., Warren, J.T., Bokesch, H., Kenney, S., Boyd, M.R., 1990. New colorimetric cytotoxicity assay for anticancer-drug screening. J. Natl. Cancer Inst. 82, 1107-1112.

Stoll, U., Barth, B., Scheerer, N., Schneider, E., Kiefer, J., 1996. HPRT mutations in V79 Chinese hamster cells induced by accelerated $\mathrm{Ni}, \mathrm{Au}$ and $\mathrm{Pb}$ ions. Int. J. Radiat. Biol. 70, 15-22.
Stoll, U., Schmidt, A., Schneider, E., Kiefer, J., 1995. Killing and mutation of Chinese hamster V79 cells exposed to accelerated oxygen and neon ions. Radiat. Res. 142, 288-294.

Strongin, D.E., Bevis, B., Khuong, N., Downing, M.E., Strack, R.L., Sundaram, K., Glick, B.S., Keenan, R.J., 2007. Structural rearrangements near the chromophore influence the maturation speed and brightness of DsRed variants. Protein Eng. Des. Sel. 20, 525-534.

Sung, T.S., Kim, M.J., Hong, S., Jeon, J.P., Kim, B.J., Jeon, J.H., Kim, S.J., So, I., 2009. Functional characteristics of TRPC4 channels expressed in HEK 293 cells. Mol. Cells 27, 167-173.

Suntharalingam, N., Podgorsak, E.B., Hendry, J.H., 2005. Basic radiobiology. In: Podgorsak, E.B. (Ed.), Radiation Oncology Physics: A Handbook for Teachers and Students. International Atomic Energy Agency Publication, pp. 485-504.

Takashi, K., 2013. Radiation-induced cell death and its mechanisms. Radiat. Emerg. Med. 2 (1), 1-4. 1-1-2013.

Tubiana, M., 2009. Prevention of cancer and the dose-effect relationship: the carcinogenic effects of ionizing radiations. Cancer Radiother. 13, 238-258.

Vellonen, K.S., Honkakoski, P., Urtti, A., 2004. Substrates and inhibitors of efflux proteins interfere with the MTT assay in cells and may lead to underestimation of drug toxicity. Eur. J. Pharm. Sci. 23, 181-188.

Verkhusha, V., 2001. An enhanced mutant of red fluorescent protein DsRed for double labeling and developmental timer of neural fiber bundle formation. J. Biol. Chem. 276, 29621-29624.

Vuckovic, M., Radojcic, M.B., Milosavljevic, B.H., 2005. Gamma-radiation induced damage of proteins in the thick fraction of egg white. J. Serb. Chem. Soc. 70 (11), 1255-1262.

Worle-Knirsch, J.M., Pulskamp, K., Krug, H.F., 2006. Oops they did it again! Carbon nanotubes hoax scientists in viability assays. Nano Lett. 6, 1261-1268.

Yang, M., Kim, J.S., Song, M.S., Kim, J.C., Shin, T., Lee, S.S., Kim, S.H., Moon, C., 2010. Dose-response and relative biological effectiveness of fast neutrons: induction of apoptosis and inhibition of neurogenesis in the hippocampus of adult mice. Int. J. Radiat. Biol. 86, 476-485.

Yu, Q., Rose, J.H., Zhang, H., Pommier, Y., 2001. Antisense inhibition of Chk2/hCds1 expression attenuates DNA damage-induced S and G2 checkpoints and enhances apoptotic activity in HEK-293 cells. FEBS Lett. 505, 7-12. 